\title{
Intra- en Interpersoonlijke EEG Coherentie bij Psychopathische Persoonlijkheidstrekken
}

\author{
Laira Donkersteeg $^{1}$, Jan Berend Deijen ${ }^{1,2}$ \\ ${ }^{1}$ Sectie Klinische Neuropsychologie, Vrije Universiteit, Amsterdam \\ ${ }^{2}$ Hersencentrum, Amsterdam
}

\section{Correspondentieadres:}

j.b.deijen@vu.nl

\section{Samenvatting}

De stoornis psychopathie wordt gekenmerkt door een cluster van persoonlijkheidstrekken (e.g. oppervlakkige charme, egocentriciteit en gebrek aan empathie) en sociaal afwijkend gedrag (e.g. impulsief gedrag en onverantwoord gedrag). Bij psychopathie worden afwijkingen gevonden in de (pre)frontale hersengebieden. In deze studie is de invloed van de mate van psychopathische persoonlijkheidstrekken op intrapersoonlijke en interpersoonlijke correlaties in frontale en temporale hersengebieden onderzocht. De correlatiematen werden bepaald aan de hand van elektro-encefalografie (EEG). De mate van psychopathische persoonlijkheidstrekken werd gemeten door middel van de Youth Psychopathic Traits Inventory (YPI). Veertien psychologiestudenten van de Vrije Universiteit Amsterdam hebben deelgenomen, waarvan 4 mannen en 10 vrouwen met leeftijden variërend tussen de 19 en 24 jaar. Uit de resultaten bleek dat YPI totaalscores niet significant samenhingen met verschillen in intrapersoonlijke correlaties in frontale en temporale gebieden tijdens sociale interactie. Daarnaast bleek dat YPI totaalscores niet significant samenhingen met verschillen in interpersoonlijke correlaties in linker en rechter frontale gebieden tijdens sociale interactie. Wel werd een significant hoofdeffect gevonden voor hemisferische zijde, waarbij linker frontale interpersoonlijke correlaties gemiddeld hoger waren dan rechter frontale interpersoonlijke correlaties, Wilk's Lamba $=.42, F(1,5)=7.00, p<.05, \eta_{p}^{2}=.58$. Tot slot bleek dat emotioneel geladen situaties de invloed van de YPI op interpersoonlijke correlaties niet significant versterkte. De beperkingen van deze studie leiden ertoe dat de bevindingen niet generaliseerbaar zijn naar de populatie mensen met psychopathie. Echter, EEG hyperscanning is een vrij nieuwe onderzoeksmethode op het gebied van psychopathie en meer onderzoek naar intra- en interpersoonlijke coherentie aan de hand van hyperscanning kan mogelijk helpen bij het verduidelijken van afwijkingen in de hersenen bij psychopathie tijdens sociale interacties. 


\section{Inleiding}

Psychopathie is een stoornis welke gekenmerkt wordt door een drietal gedragsmatige aspecten, namelijk een oppervlakkig charmante en manipulatieve interpersoonlijke stijl, een gebrek in affectieve ervaring en onverantwoordelijke gedragingen [1]. De klinische beschrijving van de stoornis wordt gekenmerkt door een cluster van persoonlijkheidstrekken en sociaal afwijkend gedrag, namelijk oppervlakkige charme; egocentriciteit; zelfzucht; gebrek aan empathie, schuldgevoel en berouw; bedrieglijk en manipulatief; gebrek aan langdurige gehechtheid aan mensen, principes of doelen; impulsief en onverantwoord gedrag; en de gewoonte om expliciete sociale normen te overschrijden $[2,3]$.

Dit brede spectrum aan psychopathische kenmerken bemoeilijkt de diagnose en maakt dat psychopathie vaak gelijk wordt gesteld aan antisociale persoonlijkheidsstoornis (ASPS) [4-6]. Echter, ondanks dat alle personen met psychopathie aan de hand van de Diagnostic and Statistical Manual of Mental Disorders (DSM, American Psychiatric Association, 1994) gediagnosticeerd kunnen worden met een antisociale persoonlijkheidsstoornis (ASPS), kunnen slechts 20\%-30\% van personen met ASPS met psychopathie worden gediagnosticeerd [7]. Naast het antisociale aspect wordt psychopathie namelijk ook gekenmerkt door een verminderde affectiviteit en emotionele reactiviteit, wat enerzijds leidt tot een verminderd vermogen om te leren door middel van straf en anderzijds tot de afwezigheid van motivatie om zich te conformeren aan vanuit de omgeving verwacht sociaal gedrag $[1,2,8]$. Over de diagnostische criteria voor psychopathie verschillen de meningen, maar de Hare
Psychopathy Checklist - Revised (PCL-R) wordt het meest gebruikt bij het diagnosticeren van psychopathie en wordt gezien als het meest valide meetinstrument $[3,5]$.

Bij ASPS en psychopathie worden specifieke afwijkingen in de structuur en het functioneren van de hersenen gevonden. Bij antisociale populaties worden structurele en functionele afwijkingen in verband gebracht met afwijkingen in de temporale cortex, de insula, de amygdala, de (para)hippocampus en de anterieure en posterieure cingulate gyrus, maar de prefrontale cortex lijkt het meest aangedaan [9]. Ook bij psychopathie blijken de afwijkingen het meest gelokaliseerd in de (pre)frontale cortex [4, $9,10]$, welke kan worden onderverdeeld in de orbitofrontale cortex (OFC), dorsolaterale prefrontale cortex (DLPFC), ventrolaterale prefrontale cortex (VLPFC) en de mediale prefrontale cortex (MPFC) [11]. Individuen met psychopathische kenmerken vertonen hypoactiviteit in de OFC en MPFC gebieden [12].

Hypoactiviteit in de OFC komt bij psychopathie voornamelijk tot uiting tijdens instrumenteel leren en tijdens het uitvoeren van coöperatie taken zoals het prisoner's dilemma paradigm [13]. De MPFC is betrokken bij instrumenteel leren en aversieve conditionering, beide functies lijken te zijn aangedaan bij individuen met psychopathie [14]. Naast afwijkingen in de (pre)frontale gebieden wordt psychopathie in verband gebracht met disfuncties in subcorticale hersensystemen $[15,16]$. In het bijzonder lijkt vroegtijdige pathologie in de amygdala samen te hangen met de ontwikkeling van psychopathie [15]. De resultaten van deze studies naar psychopathie impliceren dat disregulatie en verstoorde functionele connectiviteit in emotie-gerelateerde hersengebieden zoals de (pre)frontale 
cortex en de amygdala) ten grondslag liggen aan psychopathie $[4,9,15,16]$.

Daarnaast worden bij psychopathie specifieke afwijkingen gevonden in de hersenactiviteit, gemeten met elektroencefalografie (EEG). Binnen het EEG wordt een viertal frequentiebanden onderscheiden, namelijk bèta $(>13 \mathrm{~Hz})$, alfa $(8-13 \mathrm{~Hz})$, thèta $(4-7 \mathrm{~Hz})$ en delta $(<4$ $\mathrm{Hz})[17,18]$. In een EEG studie waarbij een psychopathische groep werd vergeleken met een niet psychopathische controlegroep, werd bij psychopathische individuen een significante hogere bèta activiteit gevonden in de OFC, de superieure frontale gyrus en de insula [19]. Deze structuren zijn gelegen in de frontale cortex, de temporale cortex en de paralimbische gebieden. De bevindingen ondersteunen de theorie dat psychopathie gepaard gaat met afwijkingen in het prefrontaal-temporaal-limbisch circuit, een circuit dat betrokken is bij leren en emotie [14, 19]. Daarnaast werd een lagere alfaactiviteit in de linker temporale gebieden waargenomen bij de psychopathische groep. Deze lagere alfa-activiteit is geassocieerd met een verminderde functionele corticale ontwikkeling [19]. Een tweede studie maakte gebruik van EEG om verschillen in corticale inhibitie tussen personen met en zonder psychopathie te meten [20]. Bij personen met psychopathie werd een significant lagere corticale inhibitie waargenomen in de DLPFC en dit wordt geassocieerd met een verminderde werking van het werkgeheugen [20]. Het werkgeheugen hangt nauw samen met doelgerichte aandacht. Bij personen met psychopathie lijkt ook deze doelgerichte aandacht aangedaan, aangezien zij minder in staat zijn om belangrijke informatie op te merken buiten hetgeen waar zij oorspronkelijk aandacht aan besteden [21]. Bij psychopathie zou DLPFC disfunctie om deze redenen kunnen leiden tot stoornissen in het reguleren van emoties en gedrag [20].

Aan de hand van EEG kan ook de mate van coherentie worden berekend [22, 23]. Coherentie wordt gezien als een maat voor synchroniciteit van neuronale activiteit en als een mogelijke reflectie van corticale connectiviteit [24]. Bij intrapersoonlijke en interpersoonlijke coherentie berekening wordt respectievelijk binnen één of tussen meerdere individu(en) de gelijktijdige activiteit van beide hemisferen of van specifieke delen van de hersenen bepaald [25]. In een fMRI onderzoek naar het verwerken van emotioneel geladen informatie werd een verschil gevonden tussen psychopathische en niet psychopathische individuen in de activiteit van de linker temporale lob, maar dit verschil werd niet gevonden in de rechter temporale lob [26]. Op basis van deze resultaten zou een onderzoek naar de intrapersoonlijke coherentie in de temporale gebieden bij psychopathie wellicht interessant kunnen zijn.

Voortbordurend op intrapersoonlijke coherentie, kan aan de hand van een relatief nieuwe scantechniek de hemisferische coherentie tussen twee personen worden gemeten, ofwel de interpersoonlijke coherentie. Deze scantechniek wordt hyperscanning genoemd [27]. De hyperscanning methode bevat een groot sociaal aspect en biedt de mogelijkheid mechanismen in het brein lokaliseren die zijn betrokken bij sociale interacties [23, 27-29]. De EEG hyperscanning methode heeft het voordeel dat personen dicht bij elkaar plaats kunnen nemen, waardoor sociale interactie op een natuurlijke wijze gemeten kan worden [28]. 
Tot op heden is met behulp van hyperscanning nog niet onderzocht op welke manier psychopathie tot uiting komt tijdens sociale interacties. Wel is bijvoorbeeld bekend dat personen met psychopathie tijdens sociale interacties ongevoelig zijn voor sociale stimuli in vergelijking met niet-psychopathische individuen [30], wat in verband zou kunnen staan met afwijkingen in activatie van de (pre)frontale cortex [9, 10, 20]. Daarnaast werd in studies naar interpersoonlijke coherentie bij niet psychopathische individuen gevonden dat de coherentie in de superieure frontale gebieden toenam bij coöperatie en imitatie taken, maar afnam tijdens competitie [27, 28]. Omdat de gebieden betrokken bij sociale interactie binnen individuen en de gebieden aangedaan bij psychopathie overlap vertonen, kan verwacht worden dat het sociale aspect bij hyperscanning de mate van interpersoonlijke coherentie beïnvloedt bij psychopathie.

In het huidige onderzoek werd de invloed van psychopathische persoonlijkheidstrekken op EEG coherentie onderzocht. Allereerst werd een verband verwacht tussen psychopathie en de mate van intrapersoonlijke coherentie. Hierbij zou een hogere mate van psychopathie samenhangen met een lagere intrapersoonlijke coherentie in frontale en temporale hersengebieden. Wat betreft interpersoonlijke coherentie werd een verband verwacht tussen psychopathie en coherentie in frontale gebieden. Een hogere mate van psychopathie zou volgens verwachting samenhangen met een lagere coherentie. Tot slot werd verwacht dat dit verband sterker is bij emotioneel geladen situaties.

\section{Methode}

\section{Deelnemers}

De groep van 14 deelnemers bestond uit 10 vrouwelijke en 4 mannelijke bachelor- of master-studenten van de opleiding Psychologie aan de Vrije Universiteit van Amsterdam (VU). De leeftijden van de deelnemers varieerde van 19 tot en met 24 jaar, met een gemiddelde leeftijd van 21.71 jaar $(S D=1.44)$. Van deze deelnemers waren er 11 deelnemers rechtshandig en 3 deelnemers linkshandig.

\section{Materialen}

Achtergrondgegevens, namelijk sekse, leeftijd en de voorkeurshand werden met een algemene vragenlijst verzameld.

YPI. De Nederlandstalige versie van de Youth Psychopathic Traits Inventory [31] is gebruikt om de mate van psychopathische trekken te bepalen. De zelfrapportage vragenlijst bestaat uit een vijftigtal directe stellingen (e.g. Ik ben vaak in de problemen gekomen omdat ik veel leugens vertelde). De antwoorden worden gescoord op een vierpunt Likert schaal van helemaal niet van toepassing (1) tot en met heel erg van toepassing (4). Een hogere score op deze items impliceert een hogere mate van psychopathische trekken. Enkele items bevatten een tegengestelde formulering (e.g. Ik word meestal verdrietig als ik andere mensen zie huilen of als ze verdrietig zijn), waarbij een hogere score op deze items een mindere mate van psychopathische trekken aanduidt. Deze items zijn omgescoord zodat een hogere totaalscore op de YPI een hogere mate en een lagere totaalscore een lagere mate van psychopathische trekken indiceert. De totaalscores op de YPI variëren tussen 50 en 200. De YPI heeft een acceptabele interne consistentie, Chronbach's alpha $=.74$ [31]. In het huidige onderzoek werd een goede interne 
consistentie verkregen, Chronbach's alpha $=.93$.

\section{EEG}

De EEG data is verkregen aan de hand van een Truscan 32 EEG-System (Deymed Diagnostic, Alien Technic, Czech Republic). Een spandex elektrodencap (Electro-Cap International, Inc.) met 19 elektrodes is gebruikt. De opnames waren monopolair, met een gelinkte oorlel referentie (4,096 Hz per kanaal). De frequentie banden waarvoor coherentie werd berekend betroffen delta $(1.5-4 \mathrm{~Hz})$, theta $(4-8 \mathrm{~Hz})$, alpha $(8-13 \mathrm{~Hz})$, en bèta (13-35 Hz). De elektrodes werden geplaatst volgens het conventionele 10/20 systeem (Jasper, 1958). De referentieplaats van de elektrodes wordt aangeduid met een letter $(\mathrm{A}=$ oorlel, $\mathrm{C}=$ centraal, $\mathrm{F}=$ frontaal, $\mathrm{Fp}=$ frontaal polaire, $\mathrm{O}=$ occipitaal, $\mathrm{P}=$ pariëtaal en $\mathrm{Z}=$ Vertex $=$ de middenlijn) en een getal waarbij oneven getallen de linkerzijde en even getallen de rechterzijde van de hersenen representeren. De referentie-elektrode werd bevestigd aan de linker oorlel en de grondelektrode aan de rechter oorlel.

De kapjes met elektrodes van de deelnemers werden aangesloten op twee aparte apparaten om de EEG data te verkrijgen. De data voor het intrapersoonlijke EEG en het hyperscanning EEG werden gelijktijdig gemeten, waarbij de EEG data van een participant achteraf werd gekoppeld aan de EEG data van de bijbehorende participant.

De verkregen EEG data werden geanalyseerd met Fast Fourier Transformation (FFT). Deze frequentie analyse geeft per elektrode weer hoe vaak er elektrische activiteit van een bepaalde frequentie is gemeten. Deze waarden zijn weergegeven in magnitude squared (uA Sq). Vervolgens werden uit deze waarden de intrapersoonlijke correlaties op alle frequenties berekend per hersengebied (e.g. frontale intrapersoonlijke correlatie werd berekend aan de hand van de linker frontale elektrodes Fp1, F3 en F7 en de rechter frontale elektrodes Fp2, F4 en F8). De interpersoonlijke (hyperscanning) correlaties werden per hemisfeer berekend op alle frequenties (e.g. frontale interpersoonlijke correlatie links werd berekend aan de hand van de linker frontale elektrodes Fp1, F3 en F7 van individu één en de linker frontale elektrodes Fp1, F3 en F7 van individu twee). De correlaties konden variëren tussen -1 en 1.

\section{Audio}

Een geluidsfragment van een huilende baby werd gebruikt om negatieve emotie en stress op te wekken. Het ervaren van negatieve emoties en stress kan een verminderde EEG coherentie teweeg brengen [32]. Een geluidsfragment van lachende mensen werd gebruikt om een positieve emotie bij de participant op te wekken. [33]. Het ervaren van positieve emoties kan EEG coherentie verhogen [32].

\section{Procedure}

Voorgaand zijn de 24 deelnemers opgedeeld in 7 tweetallen, waarvan 5 vrouwelijke koppels en 2 mannelijke koppels. Het onderzoek werd uitgevoerd in een afgesloten onderzoekskamer. Het huidige onderzoek had verschillende condities van ieder 3 minuten. De deelnemers doorliepen alle condities, zoals weergegeven in Tabel 1. Tijdens alle condities werd het EEG gemeten. 
Tabel 1

Onderzoekscondities die zijn doorlopen door elk koppel van deelnemers $(n=7)$

\begin{tabular}{lll}
\hline Conditie & Opstelling & Activiteit \\
\hline Basisconditie & Naast elkaar & Rust \\
Dialoog 1 & Tegenover elkaar & Beide deelnemers voeren een gesprek \\
Dialoog 2 & Ruggen tegen elkaar & Beide deelnemers voeren een gesprek \\
Emotie 1 & Naast elkaar & $\begin{array}{l}\text { Eén participant luistert naar gehuil, de andere naar } \\
\text { gelach }\end{array}$ \\
Emotie 2 & Naast elkaar & Beide deelnemers luisteren naar gelach \\
\end{tabular}

$\mathrm{Na}$ het aanbrengen van de apparatuur volgde allereerst een basisconditie. Tijdens deze conditie werd de EEG in rust gemeten gedurende 3 minuten. Van de deelnemers werd gevraagd om voor zich uit te kijken en zo min mogelijk te bewegen.

De eerste experimentele conditie omvatte het voeren van een dialoog. Deze conditie bestond uit twee fasen. Tijdens de eerste fase (Dialoog 1) werden de deelnemers tegenover elkaar opgesteld. Van de deelnemers werd gevraagd om oogcontact te behouden en gedurende 3 minuten een gesprek te voeren over een willekeurig onderwerp. Tijdens de tweede fase (Dialoog 2) werden de deelnemers met de ruggen naar elkaar toe opgesteld.

Vervolgens werd gevraagd om gedurende 3 minuten een gesprek te voeren over een willekeurig onderwerp.

De tweede experimentele conditie omvatte luisteren naar geluidsfragmenten. Deze conditie bestond uit een tweetal fasen. In beide fasen zaten de deelnemers naast elkaar. In de eerste fase (Emotie 1) kreeg één participant een geluidsfragment van lachende mensen te horen en de andere participant kreeg een geluidsfragment van een huilende baby te horen. In de tweede fase (Emotie 2) kregen beide deelnemers een geluidsfragment van lachende mensen te horen.
$\mathrm{Na}$ afloop van de EEG metingen kregen de deelnemers de opdracht om de Nederlandstalige versies in te vullen van de Jenkins Activity Survey (JAS) [34], de Interne Externe Beheersing Schaal [35], de HEXACO Simplified Personality Inventory (HEXACO-SPI; De Vries \& Born, 2013) en de Youth Psychopathic Traits Inventory (YPI). De YPI is gebruikt voor het huidige onderzoek.

\section{Data analyse}

De data werd geanalyseerd aan de hand van het Statistical Package for the Social Sciences (SPSS, standaard versie, 21, 2012). Bij de analyses werd een significantieniveau van $\alpha=0.05$ gehanteerd.

De eerste hypothese veronderstelt een verband tussen de mate van psychopathische persoonlijkheidstrekken en de intrapersoonlijke correlatie in frontale en temporale hersengebieden. De hypothese wordt onderzocht met een $3 \times 2$ design covariantie analyse voor herhaalde metingen (HM ANCOVA). Bij deze analyse wordt de gemiddelde EEG correlatie onder drie condities (basisconditie, Dialoog 1 en Dialoog 2) en de EEG correlaties per hersengebied (frontaal en temporaal) vergeleken. De totaalscore op de YPI wordt toegevoegd als onafhankelijke variabele (covariaat). 
De tweede hypothese betreft een verband tussen de mate van interpersoonlijke correlatie in frontale hersengebieden en de mate van psychopathische persoonlijkheidstrekken. Deze hypothese wordt onderzocht aan de hand van een $3 \times 2$ design HM ANCOVA. Bij deze analyse worden de EEG correlaties van de zeven hyperscan koppels in drie condities (basisconditie, Dialoog 1 en Dialoog 2) vergeleken met de EEG correlaties per hemisfeer (frontaal rechts en frontaal links). De verschilscores tussen de koppels op de YPI wordt in deze analyse toegevoegd als onafhankelijke variabele (covariaat).

De derde hypothese gaat uit van een versterkt verband tussen de mate van interpersoonlijke correlatie in frontale hersengebieden en de mate van psychopathische persoonlijkheidstrekken in emotioneel geladen situaties. Bij deze analyse worden de EEG correlaties van de zeven hyperscan koppels in drie condities (basisconditie, Emotie 1 en Emotie 2) vergeleken met de EEG correlaties per hemisfeer (frontaal rechts en frontaal links). De verschilscores tussen de koppels op de YPI wordt in deze analyse toegevoegd als onafhankelijke variabele (covariaat).

Voorafgaand aan de analyses werd gecontroleerd voor mogelijke verstorende factoren zoals sekse en leeftijd. Eventuele verstorende factoren werden opgenomen in de ANCOVA's.

\section{Resultaten}

\section{Beschrijvende statistiek}

In het huidige onderzoek zijn de gegevens geanalyseerd van 14 deelnemers, welke tijdens hyperscanning werden onderverdeeld in 7 koppels. De totaalscores op de YPI varieerden tussen 67 en 108, met een gemiddelde totaalscore van $83.93(S D=14.77)$. De verschilscores op de YPI tussen de koppels varieerden tussen 1 en 24 , met een gemiddelde verschilscore van $11.86(S D=10.42)$. Om te controleren op eventuele verstorende variabelen is een de mate van samenhang tussen leeftijd en sekse op de YPI scores en de EEG correlaties onderzocht. Een bivariate correlatie analyse met Pearson product-moment correlatie coëfficiënten liet een gemiddeld tot sterke samenhang zien tussen leeftijd en de totaalscore op de YPI, $r=.60, n=14, p<.05$, waarbij een hogere leeftijd geassocieerd werd met een hogere totaalscore op de YPI. Sekse bleek sterk samen te hangen met de totaalscore op de YPI, $r=.78, n=14, p<.005$. Uit een $t$-test voor onafhankelijke metingen bleek dat mannen gemiddeld hoger scoorden $(M=101.50, S D=76.90)$ op de YPI dan vrouwen $(M=76.90, S D=9.33)$, $t(12)=4.33, p<.005$. Leeftijd en sekse bleken niet statistisch significant samen te hangen met de intrapersoonlijke EEG correlaties. Voor leeftijd en sekse werd gecontroleerd in de analyse van de YPI totaalscores en de intrapersoonlijke EEG correlaties in frontale en temporale gebieden.

\section{Inferentiële statistiek}

De eerste hypothese voorspelde een verband tussen de mate van psychopathische persoonlijkheidstrekken en de intrapersoonlijke correlatie in frontale en temporale hersengebieden. Een $3 \times 2$ design covariantie analyse voor herhaalde metingen (HM ANCOVA) is uitgevoerd om intrapersoonlijke EEG correlaties te vergelijken in de basisconditie, Dialoog 1 en Dialoog 2. De beschrijvende statistiek is weergegeven in Tabel 2. Een voorafgaande assumptieanalyse toont dat de variantie en 
covarianties tussen de condities en hersengebieden gelijk is en de assumptie van sfericiteit niet werd geschonden, Mauchly's $W_{\text {Conditie*Hersengebied }}=.66, \chi^{2}$
$(2)=3.72, p=.16$. Uit een tweede analyse blijkt dat de data bij benadering normaal verdeeld is.

Tabel 2

Beschrijvende Statistiek voor Intrapersoonlijke EEG Correlaties voor Basisconditie, Experimentele Conditie Dialoog 1 en Experimentele Conditie Dialoog 2 per Hersengebied.

\begin{tabular}{|c|c|c|c|c|c|c|}
\hline & \multicolumn{3}{|c|}{ Frontaal } & \multicolumn{3}{|c|}{ Temporaal } \\
\hline & $N$ & $M$ & $S D$ & $N$ & $M$ & $S D$ \\
\hline \multicolumn{7}{|c|}{ Basisconditie } \\
\hline Man & 4 & .67 & .31 & 4 & .56 & .31 \\
\hline Vrouw & 10 & .61 & .31 & 10 & .56 & .40 \\
\hline Totaal & 14 & .63 & .30 & 14 & .56 & .34 \\
\hline \multicolumn{7}{|l|}{ Dialoog 1} \\
\hline Man & 4 & .69 & .26 & 4 & .76 & .09 \\
\hline Vrouw & 10 & .68 & .27 & 10 & .46 & .27 \\
\hline Totaal & 14 & .68 & .25 & 14 & .55 & .27 \\
\hline \multicolumn{7}{|l|}{ Dialoog 2} \\
\hline Man & 4 & .66 & .33 & 4 & .61 & .24 \\
\hline Vrouw & 10 & .73 & .22 & 10 & .39 & .31 \\
\hline Totaal & 14 & .71 & .24 & 14 & .45 & .30 \\
\hline
\end{tabular}

Allereerst is geen significant interactieeffect gevonden tussen de condities, de totaalscore op de YPI en de hersengebieden, Wilk's Lamba $=.90, F(2$, $9)=.21, p=.81, \eta_{p}^{2}=.05$. De verschillen in YPI totaalscores hangen niet samen met de verschillen in intrapersoonlijke EEG correlaties in frontale en temporale gebieden en de verschillen in intrapersoonlijke EEG correlaties tijdens de drie condities. Daarnaast bleek het interactie-effect tussen de hersengebieden en de YPI niet significant, Wilk's Lamba = $.84, F(1,10)=1.94, p=.19, \eta_{p}^{2}=.16$. De verschillen in YPI totaalscores hangen niet samen met de verschillen in intrapersoonlijke EEG correlaties in frontale en temporale gebieden. Leeftijd en sekse hadden geen significant effect op het opgestelde model, $F_{\text {Leeftijd }}(1,10)=$
$0.07, p=.80, F_{\text {Sekse }}(1,10)=0.02, p=$ .51 .

De tweede hypothese verwacht een verband tussen de mate van interpersoonlijke correlatie in frontale hersengebieden en de mate van psychopathische persoonlijkheidstrekken. Een $3 \times 2$ design HM ANCOVA is uitgevoerd om interpersoonlijke EEG correlaties in de linker en rechter frontale hemisferen te vergelijken in de basisconditie, Dialoog 1 Dialoog 2. De beschrijvende statistiek is weergegeven in Tabel 3.

Uit een voorafgaande assumptieanalyse bleken de variantie en covarianties tussen de condities en hemisferen gelijk en bleef de assumptie van sfericiteit ongeschonden, Mauchly's $W_{\text {Conditie } * \text { Hersengebied }}=.67, \chi^{2}$ 
$(2)=1.63, p=.44$. Daarnaast is de data bij benadering normaal verdeeld.

Tabel 3

Beschrijvende Statistiek voor Interpersoonlijke EEG Correlaties voor Basisconditie, Experimentele Conditie Dialoog 1 en Experimentele Conditie Dialoog 2 per Hemisfeer.

\begin{tabular}{|c|c|c|c|c|c|c|}
\hline & \multicolumn{3}{|c|}{ Links } & \multicolumn{3}{|c|}{ Rechts } \\
\hline & $N$ & $M$ & $S D$ & $N$ & $M$ & $S D$ \\
\hline Basisconditie & 7 & .53 & .32 & 7 & .46 & .31 \\
\hline Dialoog 1 & 7 & .47 & .27 & 7 & .26 & .14 \\
\hline Dialoog 2 & 7 & .49 & .24 & 7 & .26 & .28 \\
\hline
\end{tabular}

Allereerst werd geen significant interactieeffect gevonden tussen conditie, hemisfeer en de YPI verschilscore, Wilk's Lamba = $.58, F(2,4)=1.48, p=.33, \eta_{p}^{2}=.43$.

Daarnaast werd geen significant interactieeffect gevonden tussen de YPI verschilscore en de hemisfeer, Wilk's Lamba $=.68, F(1,5)=2.32, p=.18, \eta_{p}^{2}=$ .32. De verschillen in YPI totaalscores hangen niet samen met de verschillen in interpersoonlijke EEG correlaties de linker en rechter hemisferen. Vervolgens werd geen statistisch significant interactie-effect gevonden voor tussen conditie en de YPI verschilscore, Wilk's Lamba $=.91, F(2,4)$ $=.21, p=.82, \eta_{p}^{2}=.09$. Een statistisch significant hoofdeffect werd gevonden voor hemisfeer, Wilk's Lamba $=.42, F(1$, $5)=7.00, p<.05, \eta_{p}^{2}=.58$. De effectgrootte toont dat $58 \%$ van de variantie in interpersoonlijke EEG correlaties verklaard kan worden door de hemisfeer. Een post-hoc vergelijking voor simpele effecten indiceerde dat de interpersoonlijke EEG correlaties in de linker hemisfeer hoger waren $(M=$ $.50, S E=.09)$ dan de interpersoonlijke EEG correlaties in de rechter hemisfeer $(M=.33, S E=.07)$.

De derde hypothese verwacht een versterkt verband tussen de mate van interpersoonlijke correlatie in frontale hersengebieden en de mate van psychopathische persoonlijkheidstrekken bij emotioneel geladen situaties. Een $3 \times 2$ HM ANCOVA is uitgevoerd om EEG correlaties in de linker en rechter frontale hemisferen te vergelijken in de basisconditie, Emotie 1 en Emotie 2. De beschrijvende statistiek is weergegeven in Tabel 4. Uit een voorafgaande assumptieanalyse bleek dat de variantie en covarianties tussen de condities en hemisferen niet van elkaar afweken en werd de assumptie van sfericiteit dus niet geschonden, Mauchly's

$W_{\text {Conditie } * \text { Hersengebied }}=.31, \chi^{2}(2)=4.74$, $p=.09$. Doordat de data bij benadering normaal verdeeld is, werd de assumptie van normaliteit niet ernstig geschonden.

Allereerst werd geen significant interactieeffect gevonden tussen conditie, hemisfeer en de YPI verschilscore, Wilk's Lamba = $.40, F(2,4)=2.95, p=.16, \eta_{p}^{2}=.60$. De verschillen in YPI totaalscores hangen niet samen met de verschillen in interpersoonlijke EEG correlaties in linker en rechter hemisferen tijdens verschillende emotioneel geladen situaties. Daarnaast werd geen significant interactie-effect gevonden tussen de YPI verschilscore en de hemisfeer, Wilk's Lamba $=.88, F(1,5)$ 
$=71, p=.44, \eta_{p}^{2}=.12$. De verschillen in YPI totaalscores hangen niet samen met de verschillen in interpersoonlijke EEG correlaties in de linker en rechter hemisferen. Tot slot werd een marginale trend gevonden voor een interactie-effect tussen conditie en hemisfeer, Wilk's Lamba $=.32, F(2,4)=4.31, p=.10, \eta_{p}^{2}=$
.68. De variantie in interpersoonlijke EEG correlaties kan voor $68 \%$ verklaard worden door de verschillende situaties en verschillen in EEG correlaties tussen de hemisferen (zie Tabel 4). Hoofdeffecten voor conditie en hemisfeer bleken niet significant.

Tabel 4

Beschrijvende Statistiek voor Interpersoonlijke EEG Correlaties voor Basisconditie, Experimentele Conditie Emotie 1 en Experimentele Conditie Emotie 2 per Hemisfeer.

\begin{tabular}{|c|c|c|c|c|c|c|}
\hline & \multicolumn{3}{|c|}{ Links } & \multicolumn{3}{|c|}{ Rechts } \\
\hline & $N$ & $M$ & $S D$ & $N$ & $M$ & $S D$ \\
\hline Basisconditie & 7 & .53 & .32 & 7 & .45 & .31 \\
\hline Emotie 1 & 7 & .25 & .14 & 7 & .24 & .24 \\
\hline Emotie 2 & 7 & .36 & .26 & 7 & .27 & .30 \\
\hline
\end{tabular}

\section{Discussie}

In de huidige studie is getracht te achterhalen in hoeverre de mate van psychopathische eigenschappen van invloed is op de intrapersoonlijke (hemisferisch binnen een individu) en de interpersoonlijke (hemisferisch tussen twee individuen) EEG coherentie. Op grond van de onderzoeksresultaten lijken psychopathische eigenschappen echter geen invloed te hebben op intrapersoonlijke en interpersoonlijke coherenties.

Allereerst werd een verband verwacht tussen de mate van intrapersoonlijke coherentie en de mate van psychopathische persoonlijkheidstrekken. Een hogere mate van psychopathische persoonlijkheidstrekken zou hierbij leiden tot een lagere intrapersoonlijke coherentie in frontale en temporale hersengebieden. Het blijkt dat de verschillen in YPI totaalscores niet samenhangen met de verschillen in intrapersoonlijke EEG correlaties in frontale en temporale gebieden. Deze bevinding strookt niet met de verwachting gebaseerd op eerder gevonden literatuur, waarbij uit de resultaten van een fMRI onderzoek bleek dat psychopaten ongelijke activiteit vertoonden tussen temporale gebieden (Stegeren \& Everaerd, 2003).

Ten tweede werd in het huidige onderzoek een verband verwacht tussen de mate van interpersoonlijke coherentie in frontale gebieden en de mate van psychopathische persoonlijkheidstrekken. Een hogere mate van psychopathische persoonlijkheidstrekken zou volgens verwachting leiden tot verminderde coherentie in de frontale gebieden. De resultaten lieten geen verschil zien in interpersoonlijke EEG correlaties afgezet tegen YPI verschilscores. Ook dit strookt niet met de bevindingen uit eerder onderzoek, waarbij afwijkingen in de (pre)frontale cortex werden gevonden bij psychopaten in vergelijking met niet psychopathische individuen $[4,10]$. Daarnaast bleek het niet uit te maken of de 
deelnemers naast elkaar zaten en niets deden, een dialoog voerden terwijl zij elkaar konden aankijken of een dialoog voerden terwijl zij met de ruggen naar elkaar toe zaten. Ook dit strookt niet met de verwachtingen op basis van ander onderzoek, waarbij psychopaten in samenwerkingstaken of sociale activiteiten hypoactiviteit vertonen in de frontale cortex [13]. Wel bleken de hemisferische zijdes waarbij de interpersoonlijke coherenties bepaald werden significant te verschillen. Interpersoonlijke EEG correlaties tussen de linker frontale gebieden waren gemiddeld hoger dan interpersoonlijke EEG coherenties tussen de rechter frontale gebieden. De linker frontale cortex is, meer dan de rechter frontale cortex, betrokken bij de beleving en expressie van positieve emoties [36]. Een mogelijke verklaring zou kunnen zijn dat de deelnemers in meerdere mate gelijkmatig positieve emoties ervoeren dan negatieve emoties, wat leidde tot een verhoogde coherentie in de linker frontale gebieden ten opzichte van de rechter frontale gebieden.

Ten derde werd verwacht dat verschillen in interpersoonlijke EEG coherentie werden versterkt tijdens emotioneel geladen situaties. Echter, er werd geen verband tussen emotioneel geladen situaties, interpersoonlijke coherentie in frontale gebieden en de mate van psychopathische kenmerken gevonden. Een marginale trend werd gevonden voor het effect tussen de emotioneel geladen condities en de hemisferische zijdes frontaal. De variantie in interpersoonlijke EEG coherentie kan voor $68 \%$ verklaard worden door de verschillende situaties en verschillen in EEG coherentie tussen de hemisferen. In alle emotioneel geladen situaties bleken de rechter frontale EEG coherenties gemiddeld het hoogst. Daarnaast bleken de frontale EEG coherenties gemiddeld het hoogst in de neutrale basisconditie en gemiddeld het laagst in de conditie waarin koppels bloot werden gesteld aan tegenstrijdige (lachen en huilen) emotioneel geladen geluidsfragmenten. De interpersoonlijke coherentie was dus het laagst wanneer één van de deelnemers bloot werd gesteld aan een negatief emotioneel geladen geluidsfragment en de andere participant bloot werd gesteld aan een positief emotioneel geladen geluidsfragment. Zoals eerder genoemd, is de linker frontale cortex meer betrokken is bij de beleving en expressie van positieve emoties en de rechter frontale cortex in meerdere mate betrokken bij de beleving en expressie van negatieve emoties [36]. Dit verschil tussen de linker en rechter hemisfeer bij de beleving van emoties kan een verklaring zijn voor de lage frontale coherentie tijdens de conditie waarbij deelnemers gelijktijdig bloot werden gesteld aan geluidsfragmenten met van elkaar verschillende emoties.

De bevindingen in deze studie tonen niet dat de mate van psychopathische persoonlijkheidstrekken invloed heeft op de intrapersoonlijke en interpersoonlijke hemisferische coherenties. Echter, deze studie kent een aantal beperkingen die ervoor zorgen dat de bevindingen met enige voorzichtigheid geïnterpreteerd dienen te worden. Allereerst treedt een beperking op doordat in deze studie gebruik is gemaakt van een vragenlijst voor adolescenten, terwijl de populatie ook volwassenen bevat. Hoewel de YPI een valide en betrouwbaar instrument is voor het meten van psychopathische persoonlijkheidskenmerken bij adolescenten, zijn de normen niet valide en betrouwbaar voor volwassenen [31]. Daar komt bij dat de populatie van individuen met psychopathische kenmerken zeer heterogeen is [37]. Het gebruiken van een onvoldoende toepasselijke vragenlijst in 
een al zeer heterogene populatie, leidt mogelijk tot onvoldoende validiteit. Voor toekomstig onderzoek wordt dan ook aanbevolen om gebruik te maken van een meer geaccepteerd meetinstrument zoals de PCL-R, aangezien dit leidt tot meer valide metingen van de aan- en afwezigheid van de stoornis psychopathie [3]. Ten tweede, hoewel er in de huidige studie wel psychopathische kenmerken zijn gemeten, is het onduidelijk of er sprake was van psychopathie in de steekproef. In deze studie werd gebruik gemaakt van een gelegenheidssteekproef bestaande uit enkel psychologiestudenten. Daar komt bij dat de paren in dit onderzoek willekeurig zijn samengesteld en niet zijn afgestemd op basis van de YPI scores. De huidige studie is dus geen vergelijkend onderzoek tussen psychopaten en niet-psychopaten. Geconcludeerd kan worden dat de beperkingen in deze studie als gevolg hebben dat het onderzoek niet generaliseerbaar is naar de populatie psychopaten. De beperkingen van dit onderzoek zouden een mogelijke verklaring bieden voor de discrepantie tussen de bevindingen in deze studie en de resultaten uit eerder genoemde literatuur. Wel kan aan de hand van deze studie worden gesuggereerd dat het hebben van iets meer psychopathische kenmerken tussen of binnen koppels niet meteen terug te zien is bij EEG hyperscanning.

In toekomstig onderzoek naar intra- en interpersoonlijke EEG coherenties bij psychopathie is het van belang dat gebruik wordt gemaakt van een steekproef uit een klinische populatie. Op deze manier zou een groep mensen met psychopathie kunnen worden vergeleken met een controlegroep bestaande uit personen zonder psychophatie. Tot slot, hyperscanning is een vrij nieuwe onderzoeksmethode op het gebied van psychopathie. Meer onderzoek naar intra- en interpersoonlijke coherentie aan de hand van hyperscanning kan mogelijk helpen bij het verduidelijken van afwijkingen in de hersenen bij psychopathie tijdens sociale interacties.

\section{Referenties}

1. Cooke, D.J. and C. Michie, Refining the construct of psychopathy: Towards a hierarchical model. Psychological assessment, 2001. 13(2): p. 171.

2. Hare, R.D. and S.D. Hart, Psychopathy, mental disorder, and crime. 1993.

3. Hare, R.D. and C.S. Neumann, The PCL-R assessment of psychopathy. Handbook of psychopathy, 2006: p. 58-88.

4. Blair, R.J.R., Neurobiological basis of psychopathy. The British Journal of Psychiatry, 2003. 182(1): p. 5-7.

5. Millon, T., E. Simonsen, and M. Birket-Smith, Historical conceptions of psychopathy in the United States and Europe. Psychopathy: Antisocial, criminal, and violent behavior, 1998: p. 3-31.

6. Walsh, Z., Psychopathy and criminal violence: The moderating effect of ethnicity. Law and Human Behavior, 2013. 37(5): p. 303.

7. Levenson, M.R., K.A. Kiehl, and C.M. Fitzpatrick, Assessing psychopathic attributes in a noninstitutionalized population. Journal of personality and social psychology, 1995. 68(1): p. 151.

8. Glass, S.J. and J.P. Newman, Emotion processing in the criminal psychopath: the role of attention in emotion-facilitated memory. Journal of abnormal psychology, 2009. 118(1): p. 229.

9. $\quad$ Yang, Y. and A. Raine, Prefrontal structural and functional brain 
imaging findings in antisocial, violent, and psychopathic individuals: a meta-analysis.

Psychiatry Research: Neuroimaging, 2009. 174(2): p. 8188.

10. Zukov, I., R. Ptacek, and S. Fischer, EEG abnormalities in different types of criminal behavior. Activitas Nervosa Superior, 2008. 50(4): p. 110-113.

11. Öngür, D., A.T. Ferry, and J.L. Price, Architectonic subdivision of the human orbital and medial prefrontal cortex. Journal of Comparative Neurology, 2003. 460(3): p. 425-449.

12. Schutter, D., J. van Honk, and E. de Haan, Principes en toepassingen van transcraniale magnetische stimulatie in de klinische neurowetenschappen. Neuropraxis, 2002. 6(1): p. 8-13.

13. Blair, R., Dysfunctions of medial and lateral orbitofrontal cortex in psychopathy. Annals of the New York Academy of Sciences, 2007. 1121(1): p. 461-479.

14. Lapierre, D., C.M. Braun, and S. Hodgins, Ventral frontal deficits in psychopathy: Neuropsychological test findings. Neuropsychologia, 1995. 33(2): p. 139-151.

15. Blair, R., Subcortical Brain Systems in Psychopathy: The Amygdala and Associated Structures. 2006.

16. Müller, J.L., M. Sommer, V. Wagner, K. Lange, H. Taschler, C.H. Röder, G. Schuierer, H.E. Klein, and G. Hajak, Abnormalities in emotion processing within cortical and subcortical regions in criminal psychopaths: evidence from a functional magnetic resonance imaging study using pictures with emotional content.
Biological psychiatry, 2003. 54(2): p. 152-162.

17. Zietsch, B.P., J.L. Hansen, N.K. Hansell, G.M. Geffen, N.G. Martin, and M.J. Wright, Common and specific genetic influences on EEG power bands delta, theta, alpha, and beta. Biological psychology, 2007. 75(2): p. 154-164.

18. van Eijk, L., E.R. Groot, M. van Spronsen, Y.J. Maas, D. Keeser, O. Pogarell, and H.J. Engelbregt, Testing Van Gool's hypothesis: A method to predict side effects of cholinesterase inhibitors in patients with cellular degenerative and vascular dementia. Advances in Geriatrics, 2015. 2015.

19. Calzada-Reyes, A., A. AlvarezAmador, L. Galán-García, and M. Valdés-Sosa, EEG abnormalities in psychopath and non-psychopath violent offenders. Journal of forensic and legal medicine, 2013. 20(1): p. 19-26.

20. Hoppenbrouwers, S.S., D.R. De Jesus, T. Stirpe, P.B. Fitzgerald, A.N. Voineskos, D.J. Schutter, and Z.J. Daskalakis, Inhibitory deficits in the dorsolateral prefrontal cortex in psychopathic offenders. Cortex, 2013. 49(5): p. 1377-1385.

21. Baskin-Sommers, A.R., J.J. Curtin, and J.P. Newman, Specifying the attentional selection that moderates the fearlessness of psychopathic offenders. Psychological science, 2011. 22(2): p. 226-234.

22. van der Hiele, K., A. Vein, G. van Dijk, and H. Middelkoop, Kwantitatieve elektroencefalografie als hulpmiddel bij de vroege diagnostiek van Alzheimer-type dementie. Neuropraxis, 2004. 8(2): p. 39-45. 
Donkersteeg en Deijen Intra- en Interpersoonlijke EEG Coherentie bij Psychopathische Persoonlijkheidstrekken

23. Labooy-Speksnijder, C., J. Deijen, and H. Engelbregt, Persoonlijkheid en Hersenconnectiviteit, een nieuwe uitdaging? GGZ Vaktijdschrift, 2019. 2(1): p. 29-40 DOI:

https://doi.org/10.31739/GGZV.201 9.1.29.

24. Adler, G., S. Brassen, and A. Jajcevic, EEG coherence in Alzheimer's dementia. Journal of neural transmission, 2003. 110(9): p. 1051-1058.

25. van de Wassenberg, W. and N. Maurits, Klinisch neurologische toepasbaarheid van multikanaalseeg. Neuropraxis, 2009. 13(2): p. 36-42.

26. van Stegeren, A. and W. Everaerd, Amygdala in beeld'De emotionele kameleon. Neuropraxis, 2003. 7(6): p. 165-171.

27. Scholkmann, F., L. Holper, U. Wolf, and M. Wolf, A new methodical approach in neuroscience: assessing interpersonal brain coupling using functional near-infrared imaging (fNIRI) hyperscanning. Frontiers in human neuroscience, 2013. 7: p. 813.

28. Cui, X., D.M. Bryant, and A.L. Reiss, NIRS-based hyperscanning reveals increased interpersonal coherence in superior frontal cortex during cooperation. Neuroimage, 2012. 59(3): p. 24302437.

29. Hirata, M., T. Ikeda, M. Kikuchi, T. Kimura, H. Hiraishi, Y. Yoshimura, and M. Asada, Hyperscanning $M E G$ for understanding motherchild cerebral interactions. Frontiers in human neuroscience, 2014. 8: p. 118.

30. Adolphs, R., Cognitive neuroscience of human social behaviour. Nature Reviews

Neuroscience, 2003. 4(3): p. $165-$

178.

31. Andershed, H.A., M. Kerr, H.

Stattin, and S. Levander, Psychopathic traits in non-referred youths: A new assessment tool. 2002.

32. Hinrichs, H. and W. Machleidt, Basic emotions reflected in EEGcoherences. International Journal of Psychophysiology, 1992. 13(3): p. 225-232.

33. Cryer, B., R. McCraty, and D. Childre, Pull the plug on stress. harvard business review, 2003. 81(7): p. 102-107.

34. Jenkins, C.D., S. Zyzanski, and R.H. Rosenman, Manual for the Jenkins activity survey. New York: Psychological Corporation, 1979.

35. Andriessen, J. and J. Van Cadsand, Een analyse van de Nederlandse IE-schaal. Nederlands Tijdschrift voor de Psychologie en haar Grensgebieden, 1983.

36. van Strien, J., De neuropsychologie van emoties. Neuropraxis, 2000. 4(5): p. 94-101.

37. Brinkley, C.A., J.P. Newman, T.A. Widiger, and D.R. Lynam, Two approaches to parsing the heterogeneity of psychopathy. Clinical Psychology: Science and Practice, 2004. 11(1): p. 69-94. 